\title{
Nature of water bonding in hydrated milk-protein systems
}

\section{Elena Goncharuk1, Galyna Polishchuk², Iryna Shevchenko², Tetiana Osmak ${ }^{2}$}

\author{
1 - 0.0. Chuyko Institute of Surface Chemistry, Kyiv, Ukraine \\ 2 - National University of Food Technologies, Kyiv, Ukraine
}

Keywords:

Milk

Protein

Water

Bonding

Concentrate

Article history:

Received

21.07.2019

Received in revised

form 12.11.2019

Accepted

30.03 .2020

Corresponding

author:

Tetiana Osmak

E-mail:

osmaktg@ukr.net

DOI:

$10.24263 / 2304$

974X-2020-9-1-10

\section{Abstract}

Introduction. The nature of the connection and the characteristics of the process of relaxation of clusters and water domains in milk and protein systems was investigated in order to predict their functional and technological properties.

Materials and methods. The relaxation features of water clusters and domains in colloidal solutions of milk proteins were studied by the thermo-stimulated depolarization method (TSD). Electrophoretic analysis of the fractional composition of milk proteins was performed according to modified Laemmli method.

Results. The peculiarities of water distribution in bulk protein matrices in milk and in hydrated milk protein concentrates by TSD were studied. On the basis of comparative analysis of TSD spectra of relaxation of dipole structures of water in low-temperature and high-temperature regions in samples of fresh skimmed milk, reconstituted skimmed milk powder and sodium caseinate solution, a significant difference in the nature of water cluster formation in these systems is proved. Milk protein concentrates with reduced energy of activation of depolarization of water in the hydrated state are found to form spatial grids with smaller cell sizes than proteins of natural milk. The revealed effect is explained by the fact that under the influence of heat treatment and drying there are significant conformational changes of protein compounds caused by the denaturation of the majority of serum proteins, in particular, immunoglobulins, serum albumin, $\beta$-lactoglobulin and $\alpha$-lactalbumin. It is relevant to use in composition of foods milk protein concentrates, whose protein matrices have spatial limitations and hold water clusters smaller than that of natural milk. The results of the research are of practical importance as they allow the purposeful formation and stabilization of the spatial structure of protein-containing food systems.

Conclusions. The peculiarities of the nature of water bonding in hydrated milk-protein systems of different degrees of heat treatment have been established. 


\section{Introduction}

In biological systems, water is distributed in the form of fragments of structures of different sizes - clusters $(<1 \mathrm{~nm})$ and domains $(\geq 1 \mathrm{~nm})$ [1]. The change in the distribution in the protein-containing systems of water domain domains leads to a shift in the ratio between "free" and "bound" water, and thus significantly affects the structure of these protein-containing systems [2]. Spatial protein gels are capable of holding water domains in the sizes from 1 to $100 \mathrm{~nm}$, thereby counteracting the gradual phase separation over time as well as the growth of ice crystals in the process of freezing [3]. This effect is extremely important for the purposeful influence on the processes of formation and stabilization of the structure of food systems [2].

Identify the content of "bound" water and the distribution of fragments of its structure can be by studying the dependence of the relaxation response of the molecules (depolarization) on the physical and chemical properties and the content of the filler in the disperse system [1]. Large-sized water domains with a number of water molecules> 1000 are relaxed in the high-temperature region of the spectrum $\left(\mathrm{HT}, 95^{\circ} \mathrm{C}<\mathrm{T}<0{ }^{\circ} \mathrm{C}\right)$. The smallest clusters $(\mathrm{R}<0.5 \mathrm{~nm})$ can be attributed to structures that contain 4-6 molecules of water and are localized between adjacent primary particles in aggregates [2], their relaxation is observed in the low-temperature (LT) region of the spectrum. The distribution of the cluster radius with the number of molecules up to several dozen occurs within $0.5<\mathrm{R}<1 \mathrm{~nm}$. The spatial constraints of relaxing dipole structures lead to the dependence of the relaxation characteristics on the sizes of these structures [3].

Despite the fact that the properties of bound water in milk and milk products were studied by many scientists $[4,5]$, the distribution of bound water in these systems as fragments of the structure has not yet been investigated. It should also be noted that such physical properties of milk proteins as solubility, the nature of the interaction between themselves and the aquatic environment, and the ability to form spatial structures are significantly dependent on the conditions of the previous thermal, mechanical and biochemical treatment of milk [6]. It is clear that the main structural factor affecting the relaxation properties of water in protein solutions is the size of its domains, which depend on the content of micelle casein (average size $0.1 \mu \mathrm{m}$ ) and their distribution in the volume of hydrated systems [7]. Thus, the study of the peculiarities of water distribution in the matrices of milk proteins of various composition and degree of purification is an actual direction of scientific research. The practical significance of the results of such a study is to use them as a tool for predicting the behavior of proteins of varying degrees of processing in food systems.

The aim of the research was to study the effects of water state in milk protein systems on their physico-chemical characteristics.

The tasks of the research are:

- to justify applying the method of thermo-stimulated depolarization to study the peculiarities of water distribution in bulk protein matrices in protein-containing food systems;

- identify the impact of pre-treatment on the physico-chemical properties of milk proteins and milk protein concentrates. 


\section{Materials and methods}

\section{Materials}

Reconstituted skimmed milk powder [5] and hydrated caseinat sodium [8] were selected. The mass fraction of dry matter in both samples of solutions of milk-protein concentrates was $10 \%$. Fresh skimmed milk with a mass fraction of fat $0,05 \%$ was used as control.

\section{Methods}

\section{Method of thermostimulated depolarization}

TSD spectra of the samples studied in the form of tablets of $30 \mathrm{~mm}$ in diameter and $\approx 1 \mathrm{~mm}$ in thickness were measured at a temperature range of $-183-0{ }^{\circ} \mathrm{C}$ for polarization voltage of 200 $\mathrm{V}$ and a heating rate of $3{ }^{\circ} \mathrm{C} / \mathrm{min}$ on a device for the production of SKB in the city of Angarsk (RF) . In the process of heating with an electrode, the strength of the depolarization current was measured in the range $10^{-14}-10^{-7} \mathrm{~A}$, which was fixed on the computer. The errors were: for temperature $-\delta_{T}= \pm 2{ }^{\circ} \mathrm{C}$; for current $-\delta_{l}= \pm 5 \%$; for the heating rate $-\delta_{h}= \pm 5 \%[1,3]$.

The activation energy of the proton conductivity $\left(\mathrm{E}_{a}\right)$ for the TCD was calculated from the Arrhenius equation [10]:

$$
\frac{d \ln I}{d T}=\frac{\mathrm{E}_{a}}{R T^{2}}
$$

where I - current of proton conductivity, A; T - temperature, $\mathrm{K} ; \mathrm{R}$ - universal gas constant.

TSD spectra were analyzed both in low temperature (LT) and in high-temperature (HT) areas.

The decomposition of the TSD spectra into components of the Gauss function was performed according to the Peakfit Origin 7.0 program [3]. On the drawings of the TSD-spectrum points, the experimental values of the depolarization current value were obtained, the thin lines denote individual relaxation peaks, and the fat curve is the result of all obtained by the decomposition of individual peaks. The degree of correlation between experimental data and mathematically expanded curves in all cases was within the range from 0.96 to -0.99 . Calculations of the distribution of clusters $(<1 \mathrm{~nm})$ and domains $(1-100 \mathrm{~nm})$ of bound water in size were performed using the TSD-cryopormetry method $[9,10]$.

\section{Method electrophoretic analysis of the fractional composition of milk proteins}

An electrophoretic analysis of the fractional composition of milk proteins was performed using the modified Laemmli method using a concentration gel for protein distribution in the range of molecular weights of $10000 \mathrm{Da}$ to $150000 \mathrm{Da}$ [11]. Treatment of electrophoregrams obtained by disc-electrophoresis was performed using the ImageMaster TotalLab v.2.01 (Amersham Biosciences) program [3].

\section{Results and discussion}

Investigation of the bond nature and the peculiarities of the water molecules relaxation in milk-protein systems by the TSD method

A comparative analysis of the obtained TCD spectra of fresh skimmed milk, reconstituted skimmed milk powder and colloidal sodium caseinate solution (Figure 1) convincingly proves a significant difference in the nature of the cluster formation of water in these systems. 

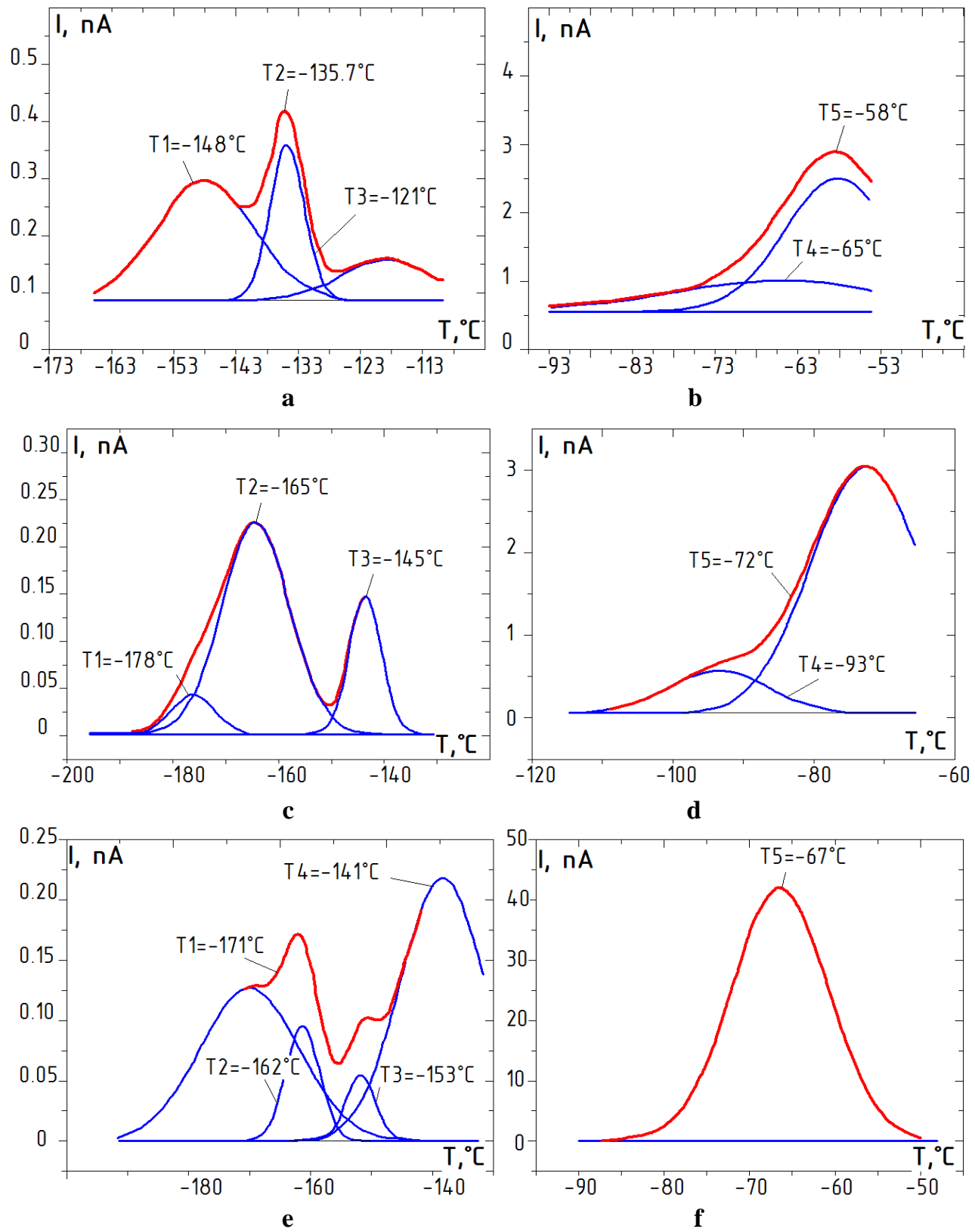

Figure 1. LT and HT areas of the TSD spectra:

a - high-temperature regions in samples of fresh skimmed milk;

b - low-temperature region in samples of fresh skimmed milk;

c - high-temperature regions in samples of skimmed milk, reconstituted;

d - low-temperature region in samples of skimmed milk, reconstituted;

e - high-temperature regions in samples of aqueous sodium caseinate;

f - low-temperature region in samples of aqueous sodium caseinate of fresh skimmed milk (a, b), skimmed milk, reconstituted (c, d) and aqueous sodium caseinate (e, f). 
Thus, in the low temperature area of the spectrum, the relaxation maxima for domains (clusters) of water molecules are observed in reconstituted milk and sodium caseinate solution at lower temperatures than in a sample of fresh milk. In this temperature range, their Ea depolarization is in the range of 5 to $10 \mathrm{~kJ} / \mathrm{mol}$, indicating the relaxation of water molecules in small clusters (up to 10 molecules). Instead, such clusters are not observed in natural milk.

The third relaxation maximum coincides with similar peaks of relaxation in natural milk. In the $\mathrm{BW}$ region of the spectrum, 2 relaxation maxima are observed at -93 and $-72{ }^{\circ} \mathrm{C}$, which is also characteristic of natural milk, but they are somewhat shifted to a lower temperature region, indicating the formation of water molecules smaller in size in the aqueous solution of reconstituted skimmed milk.

Comparison of the integral intensities for peaks observed in the TCD spectrum of skimmed milk powder (Figure 1, b) in the LT area of the spectrum indicates, firstly, the symbiosity of the relaxation processes occurring in both systems and, secondly, on the essential differences in the nature of the distribution of water inside the protein matrix of dry milk compared with natural milk. In view of the detected effect, it can be assumed that the "cells" of the net formed by the milk proteins of dry milk, when reconstituted in water, become less than in natural milk.

The TSD spectrum of aqueous suspension of sodium caseinate (Figure 1e, f) differs from the spectrum of the reconstituted skimmed milk by the presence (Figure $1 \mathrm{c}, \mathrm{d}$ ) in LT area of 4 relaxation maxima at temperatures of $-171,-162-153$ and $-141{ }^{\circ} \mathrm{C}$, the integral intensities of which are approximately one order higher than for the peaks of reconstituted dry milk. This indicates that the number of relaxation structures (clusters and water domains) formed in the presence of casein is an order of magnitude larger than that of reconstituted milk (in the region of the spectrum of the LT). The same dependence was observed in the HT area of the spectrum, in which there is one relaxation maximum at $-67^{\circ} \mathrm{C}$ of an almost ideal Gaussian species with an integral intensity of an order of magnitude higher than that of reconstituted milk.

The explanation of the intensity of the TSD spectrum in both HT and LT areas may consist in the fact that during heat treatment, especially at temperatures of $100{ }^{\circ} \mathrm{C}$, dephosphoric and dehydration of casein, its complexation with denatured whey proteins, lactose, etc., occurs. as a result of which casein micelles disintegrate or increase the size. During hydrolysis, in the first place, $\chi$-casein, for high temperatures glycemacropeptides are released, reducing the degree of hydration of casein mixtures, thermal dephosphorylation reduces the ability of casein to bond calcium, micelles destabilize and polymerize $[12,13]$.

\section{Electrophoretic analysis of the fractional composition of milk proteins}

With another study of the change in the fractional composition of milk proteins under the influence of technological treatment, the electrophoregram of milk was analyzed, which was shown in Figure 2.

Table 1 shows the fractional composition of fresh milk and reconstituted milk, which confirm the decrease in total protein in milk and significant changes in the fractional composition of proteins under the influence of technological treatment. 


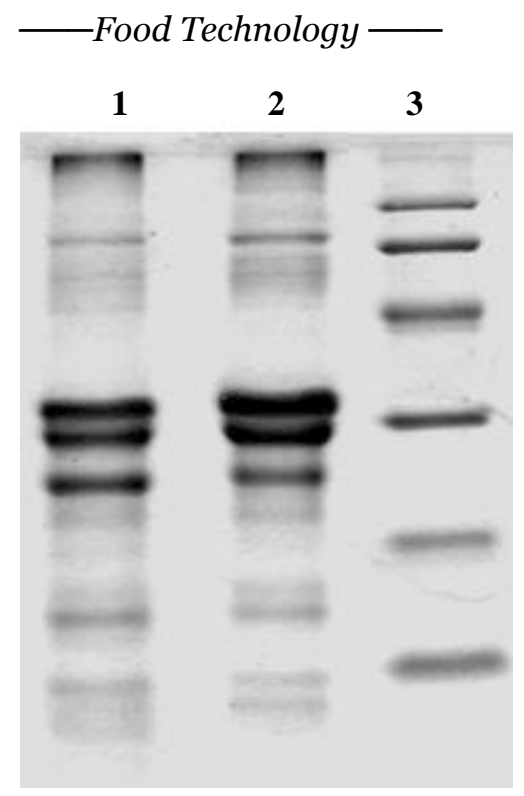

Figure 2. Electrophoregram of milk samples

1 - fresh milk; 2 - reconstituted milk; 3 - markers of molecular weight $(94,67,43,30,20,14.4 \mathrm{kDa})$.

Fractional composition of fresh milk proteins and reconstituted milk

Table 1

\begin{tabular}{|c|c|c|}
\hline \multirow{2}{*}{ Molecular weight fraction, kDa } & \multicolumn{2}{|c|}{ Concentration of the fraction, mg / $\mathbf{c m}^{\mathbf{3}}$} \\
\cline { 2 - 3 } & Raw milk & Reconstituted milk \\
\hline $150-137$ & 0.624 & 0.09 \\
\hline $118-114$ & 0.42 & 0.382 \\
\hline $91-89$ & 0.85 & 0.801 \\
\hline $86-83$ & 2.732 & 2.479 \\
\hline $76-74$ & 0.839 & 0.606 \\
\hline $67-63$ & 1.271 & - \\
\hline $30-29$ & 11.623 & 5.712 \\
\hline $28-27$ & 8.755 & 6.386 \\
\hline $25-23$ & 4.09 & 3.1 \\
\hline 18 & 2.63 & 0.602 \\
\hline $15-14$ & 3.857 & - \\
\hline $12-10$ & 2.81 & - \\
\hline Сума & 40.5 & 21.45 \\
\hline & & \\
\hline
\end{tabular}

The listed relative content of the main fractions of milk proteins to the total protein content in the investigated samples before and after heat treatment is given in Table 2. 
Fractional composition of milk proteins

\begin{tabular}{|l|c|c|}
\hline \multirow{2}{*}{ Fraction name } & \multicolumn{2}{c|}{ Content, \% } \\
\cline { 2 - 3 } & Raw milk & Reconstituted milk \\
\hline Casein & 60.4 & 70.8 \\
\hline$\beta$-lactoglobulin & 6.4 & 2.8 \\
\hline$\alpha$-lactalbumin & 9.5 & 6.0 \\
\hline Lactoferrin & 2.07 & 2.8 \\
\hline immunoglobulins of class G & 1.54 & - \\
\hline albumin & 3.1 & - \\
\hline$\gamma$-casein $(12-10 \mathrm{kDa})$ & 6.9 & - \\
\hline minor proteins & 10.09 & 12.48 \\
\hline
\end{tabular}

It is confirmed that in samples of the reconstituted milk separate fractions disappear, namely albumin, class $\mathrm{G}$ immunoglobulins and $\gamma$-casein. The content of $\beta$-lactoglobulin and $\alpha$-lactalbumin is reduced by about $40 \%$. The content of casein fractions is almost unchanged. Consequently, under the influence of heat treatment and drying, there are significant conformational changes in proteinaceous compounds caused by the denaturation of most serum proteins, in particular, immunoglobulins, serum albumin, $\beta$-lactoglobulin and $\alpha$ lactalbumin. Almost constant content of casein against the background of a significant decrease in the total protein in milk can be attributed to other scientists by the process of complexation between denaturized $\beta$-lactoglobulin with $\alpha$-lactalbumin and thermostable $\chi$ casein with disulfide bridges, although other types of bonds are not denied $[12,13,14,15]$

The dispersion of protein particles after aggregation and drying on average decreases, respectively, by 2.3 and 2.5 times. Pre-treatment and drying of milk cause slight changes in the structure of casein micelles, but after the restoration of dry milk in water there is a denser, compared with the initial milk, packaging micelle. This effect can be related to the denaturation of serum proteins and the interaction of casein micelles with calcium salts, which leads to more structuring of the system [13].

Consequently, skimmed milk, and casein, can form "cells" in spatial networks of smaller sizes than those observed in the TSD spectra of natural milk [16]. This is confirmed by the fact that the intensity of the relaxation maxima observed at -176 and $-165,-170$ and $162{ }^{\circ} \mathrm{C}$, are correlated with each other and higher than the relaxation peaks in natural milk in the LT area.

The revealed effect has practical significance for understanding the patterns of formation of the structure during low-temperature processing of protein-containing systems [17]. Excessive freezing of free water with the formation of ice crystals in excess of 60 microns leads to the appearance of a coarse-crystalline structure in food systems $[18,19]$. Therefore, it is expedient to use in the composition of foodstuffs milk-protein concentrates, protein matrices which have spatial constraints and keep clusters of water smaller than those for natural milk. 


\section{Conclusions}

It was found using the method of TSD that dry milk protein concentrates (dried skim milk and sodium caseinate) in hydrated form produce spatial mesh with smaller cell sizes than natural protein, due to conformational changes of protein macromolecules under high temperature during the process of thickening and drying.

The TSD method allows obtaining information on the interaction of dairy proteins with a dispersion medium as moisture-retaining bulk matrices in food systems for the purposeful regulation of their physico-chemical characteristics.

\section{Reference}

1. Gun'ko V.M., Zarko V.I., Goncharuk E.V. et al. (2007), TSDC spectroscopy of relaxational and interfacial phenomena, Adv. Colloid Int. Sci, 131(1-2), pp. 1-89.

2. Turov V.V., Gunko V.M. (2011), Clustered water and ways to use it, Kyiv.

3. Goncharuk O.V., Zarko V.I., Polischuk G.E. (2013), Influence of structural factors on the processes of water relaxation in dairy products with different fat content, Chemistry, Physics and Surface Technology, 4(2), pp. 226-234.

4. A 100-Year Review: Progress on the chemistry of milk and its components (2017), Madison, DOI: 10.3168/jds.2017-13250.

5. Rybak O. (2014), The role of milk proteins in the formation of dairy products. Ukrainian Food Journal, 3(3), pp. 350-360.

6. Chagarovsky O.P. (2013), Chemistry of dairy raw materials, Odesa.

7. Havea P. (2006), Protein interactions in milk protein concentrate powders, Int. Dairy J., 16, pp. 415-422.

8. Peraus F., Depping V. [et al.]. (2018), Modeling of heat stability and heat-induced agglutination of casein micelles in concentrated skim milk using a Weibullian model, Joseph Dumpler International Journal of Dairy Technology, 71(3), pp. 601-612.

9. Gun'k V.M., Turov V.V., Leboda R. [et al.]. (2007), Adsorption, NMR and Thermally Stimulated Depolarization Current Methods for Comparative Analysis of Heterogeneous Solid and Soft Materials, Langmuir, 23(6), pp. 3184-3192.

10. Yamamoto T., Endo A. [et al.]. (2005), Evaluation of thermoporometry for characterization of mesoporous materials, J. Colloid Interface Sci., 284, pp. 614-620.

11. Laemmli K. (1970), Cleavage of structural proteins during the assembly of the bacteriophage T4 head, Nature, 227(1), pp. 680-655.

12. Ostroumova T.L., Galstyan A.G., Trifonov I.U., Ravnyshkin S.A., Kulinchik I.G. (2007), Technological properties of protein concentrates, Cheese and butter, 2, pp. 53 55.

13. Donato 1., Fanny Guyomarc'h F. (2009), Formation and properties of the whey protein / $\kappa$-casein complexes in heated skim milk, J. Dairy Sci. Technol, 89, pp. 3-29.

14. Posudin Y., Kostenko V. (2015), Infrared spectroscopy of milk, Ukrainian Food Journal, 4(3), pp. 377-389.

15. Yukalo V., Datsyshyn K., Krupa O., Pavlistova N. (2019), Obtaining of $\beta$-LG, $\alpha$-LA and BSA protein fractions from milk whey, Ukrainian Food Journal, 8(4), pp. 788-798.

16. Alexander M., Dalgleish D.G. (2005), Interactions between denatured milk serum proteins and casein micelles studied by diffusing wave spectroscopy, Langmuir, 21, pp. $11380-11386$. 
17. Gun'ko V.M., Turov V.V., Bogatyrev V.M. [et al.]. (2005), Unusual properties of water at hydrophilic/hydrophobic interfaces, Adv. Colloid Interface Sci., 118, pp. 125-172.

18. Zohuriaan-Mehr M.J., Pourjavadi A., Salimi H., Kurdtabar M. (2009), Protein- and homopoly (amino acid)-based hydrogels with super-swelling properties, Polym. Adv. Technol, 20, pp. 655-671.

19. Capitani D., Crescenzi V., De Angelis A.A., Segre A.L. (2001), Water in hydrogels. An NMR study of water/polymer interactions in weakly cross-linked chitosan networks, Macromolecules, 34, pp. 4136-4144. 